\title{
Modelling Forest Growth Indices on Vegetation Pattern Formation
}

\author{
Peter Kwesi Nyarko, Christiana Cynthia Nyarko* \\ Department of Mathematical Sciences, Faculty of Engineering, University of Mines and Technology, Tarkwa, Ghana
}

Email address:

ccnyarko@umat.edu.gh (C. C. Nyarko)

${ }^{*}$ Corresponding author

\section{To cite this article:}

Peter Kwesi Nyarko, Christiana Cynthia Nyarko. Modelling Forest Growth Indices on Vegetation Pattern Formation. American Journal of Applied Mathematics. Vol. 9, No. 4, 2021, pp. 108-122. doi: 10.11648/j.ajam.20210904.13

Received: July 16, 2021; Accepted: July 24, 2021; Published: August 2, 2021

\begin{abstract}
Forest dynamics is mostly concerned with the changes in forest structure and composition over time, including its behavior in response to anthropogenic and natural destructions which is one of the primary evidence of forest change. This study presents the dynamics of vegetation pattern formation taken into account all the interaction measure indices such as light, water, temperature and nutrients fertility. Michaelis-Menten Kinetics and a Continuous-Time Markov (CTM) method were employed to determine plant metabolism responses to all the inputs. The Continuous-Time Markov (CTM) technique was then used to obtain a simple plant growth component by synthesizing the four - measure indices or resources (light, water and nutrients and temperature). Stability analysis of the formulated model was carried out to determine the possible phase regions associated with the various stability states for a sufficiently precise representation of the essential features of the model. Results of the $\beta$ values for the spatial patterns obtained indicate association or interaction among the various soil fertility levels under different water conditions. For instance, a $\beta$ value of 0.05605 represents control fertility under arid conditions, indicates a vegetation pattern with numerous and wider patches of bare or almost bare land compared to patterns exhibited by the other fertility levels.
\end{abstract}

Keywords: Vegetation, Pattern, Control Fertility, Low Fertility, Average Water, Aridity

\section{Introduction}

Human activities affect forest growth in many diverse ways by influencing the vegetation composition, cover, age and density. This changes the kind of stands present and their spatial arrangement, which affects the movement of water, animals, soils and wind. The Tropical Forestry Action Plan of the FAO in 1985 contends that 7.5 million hectares of closed forest and 3.8 million hectares of open forest are cleared in the tropics each year. Tree growth and forest destructions are primary evidence of forest dynamics. These are determined by resources like radiation, water, nutrients supply and environmental conditions such as temperature, soil acidity, air pollution and human activities. Vegetation patterns occur in many semi-arid regions of the world, including Africa [1, 2], Australia [3, 4], North America [5, 6], the Middle East [7, 8], and Asia [9]. Such patterns consist of vegetated regions separated by bare ground. They are usually labyrinthine or spotted on flat terrain, but on slopes the typical form is stripes running parallel to the contours, known as "banded vegetation" or "tiger bush" [10-12]. Some of the researchers in this field include [13]. They investigated the formation and spread of isolated regions of patterned vegetation within an unvegetated background state on flat terrain in semi-arid environment. Others include Deblauwe et al., [1]; Dralle et $a l$. , [14] in their study asserted that, slope can have a major effect on processes governed by water redistribution, due to the downhill flow of water both on the surface and within the soil. In the early 1960 s, there was a paradigm shift and studies on forest growth were more into the modelling of nutrient uptake as a key component for plant growth. Bouldin [15] and Olsen et al., [16] proposed mathematical models to simulate diffusion of solutes through soils, which were used to explain phosphate movement and uptake. Nye and Spiers [17] subsequently developed the partial differential equations used to describe simultaneous mass flow and diffusion for nutrient uptake by a unit length of 
root. Nye and Marriot [18] defined boundary conditions for the equations and solved them numerically, while Baldwin et al. [19], on the other hand, solved the equations analytically with steady state approximations. Their work became the foundation for mechanistic nutrient uptake models. Building on this, Barber and Cushman [20], Smethurst et al. [21] and Comerford et al. [22] proposed model revisions to cover the major sub-processes of nutrient uptake and to accommodate a variety of additional conditions. Other researchers such as Wu et al. [23]; Wu et al. [24] and Sharpe et al. [25] modelled the physical growth of the forest by considering the influence of stem, crown and roots. Others just considered the effect of either one of the following: availability of light, surface water or nutrients to the growth of the tree and subsequently to the growth of the forest. The forest stand consists of trees with different diameters and heights which depend on a lot of unsearchable genetic and environmental factors. Its dynamics is affected by many processes and varies among stands [26]. Information about forest composition which is often inferred through modelling studies is therefore fundamental for understanding rainforest resilience and dynamics.

\section{Environmental and Economic Values of the Forest}

It is becoming increasingly clear that, forest that are managed in a sustainable manner are able to produce both high quality wood products and other ecological goods and services such as water purification, wildlife habitat and carbon sequestration. In similar manner, the forest also has natural economic values that are often overlooked by society. Thus, when the forest is degraded, there is a financial cost incurred by society to replace the lost ecological goods and services through; increased water treatment cost, increased illness and health care costs due to decreased water and air quality, decreased property value due to degraded aesthetic qualities and also, decrease revenues from tourism and other non-timber commercial activities associated with healthy ecosystems. It is therefore worth noting that the contribution of forest to the economy, environment and social well-being of the society is significant and therefore forms an important part of our roots as a society and a big part of our future. (Natural Resources Canada, 2006).

In recent times, almost all vegetation modelling studies have been redirected to pattern formation. It is assumed that pattern formation, is from a starting point of uniform vegetation, as a response to a decrease in mean annual rainfall and human activities. Many authors have additionally investigated the subsequent transitions between different patterned states when environmental conditions such as rainfall are varied $[12,27]$. Studies on the vegetation is now concentrated on pattern formation. In addition to this, they are very important and serve as potential early warning signals of climate change and imminent regime shifts [2830]. Therefore, they have been the subject of intensive study over the last decade.

This paper presents the dynamics of the forest by determining the influence of the interactions among multiple indices such as light, water, temperature and nutrients on vegetation pattern formation using Continuous Time Markov Chain.

\section{Model Development}

In this paper, the Klausmeier [31] model of regular and irregular patterns in semiarid vegetation was modified. The Klausmeier model consists of biomass dynamics equation and water dynamics equation which is considered to be responsible for pattern formation. In his model, the water dynamics equation is controlled by a uniform supply of water at rate $A$, and loss of water due to evaporation at rate $L W$. Water uptake by plant was represented by an expression $R G(W) F(N)=R W N^{2}$ where $G(W)=W$ represents the functional response of plants to water, $F(N)=N$ represents an increasing function that describes how plants increase water infiltration. The biomass dynamics equation, is governed by biomass accumulation $J R W N^{2}$ where $J$ is the yield of plant biomass per unit water consumed, loss of plant biomass through densityindependent mortality and maintenance at a constant rate $M N$ and biomass movement due to spatial components. Klausmeier [31] model therefore consists of two state variables: a water variable (W) and plant Biomass variable (N) defined on an infinite two-dimensional domain indexed by $\mathrm{X}$ and $\mathrm{Y}$. The model is therefore a system of two partial differential equations given by Equation (1)

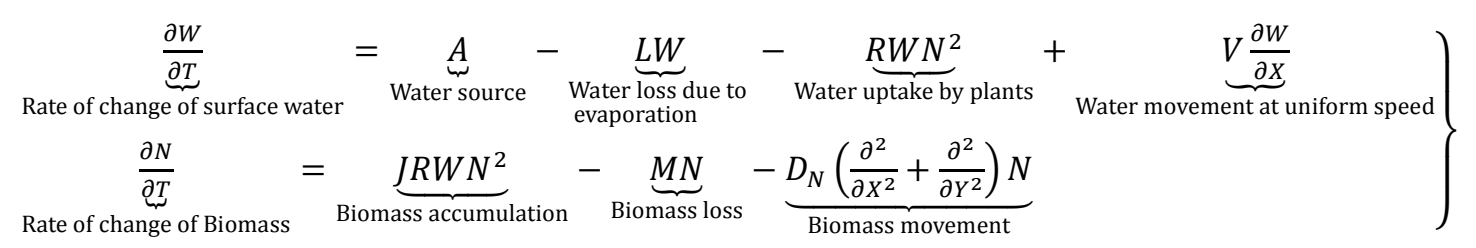

where $T$ is the time coordinate, and $(X, Y)$ represents the spatial domain.

In this paper, the water dynamics equation of the Klausmeier [31] model has been put in two-fold: the surface water dynamics and the soil water dynamics. It is presumed that, the soil water dynamics is different from surface water dynamics and hence the two cannot be merged together. This is due to the fact that, these two operate at different time scales and must be considered as two separate entities. The proposed model in this study therefore seeks to address this deficiency. The Klausmeier's [31] model is further refined in this paper by use of Li et al. [32] model for comprehensive analysis. 


\subsection{Refining the Model}

This study considered modifying the water dynamics equation of Klausmeier [31] model by separating it into two: the surface water dynamics (component) and soil water dynamics (component) and merged them with the third equation which is the biomass density component to obtain a system consisting of three equations.

\subsubsection{Surface Water Dynamics}

During and after an intense rainfall, a major proportion of the rainfall first collects above ground. This is as a result of relatively slow process of water infiltration into the soil. This water will either infiltrate into the soil or flow towards other areas and subsequently infiltrate in those regions (surface water motion). The amount of water on the soil surface at a particular position and time is denoted by $W(t, x, y)$. The rate of change of the amount of water on the surface given by $\frac{\partial W}{\partial t}$ is controlled by a uniform supply of water at rate $A$, loss of water due to evaporation at rate $L W$, surface water infiltration into the soil and the expression $V \frac{\partial W}{\partial X}$ that represents downhill water flow and measures slope gradient or $D_{W}\left(\frac{\partial^{2} W}{\partial X^{2}+\frac{\partial^{2} W}{\partial Y^{2}}}\right)$ that represents the net displacement of surface water on a perfectly horizontal terrain during rainfall. According to Walker et al. [33], infiltration rate $N_{f}(t, x, y)$ depends on the amount of water on the surface, plant density, and soil characteristics. The surface water infiltration into the soil is therefore a saturation function represented as in Equation (2).

$$
\text { Surface Water Infiltration Rate }=J W(x, y, t) \times \frac{P(x, y, t)+s_{2} N_{0}}{P(x, y, t)+s_{2}}
$$

where $P(x, y, t)$ represents the plant population (biomass) density, $J W(x, y, t)$ describes maximum infiltration rate of surface water, $\operatorname{JW}(x, y, t) N_{0}$ is the minimum water infiltration in the absence of plants and $s_{2}$ is a half-saturation constant. Parameter $s_{2}$ corresponds to the rate at which water infiltration increases with plant density. When the expression on the right-hand side of Equation (2) is substituted for surface water infiltration into the soil, the surface water dynamics of the proposed model in this research is represented by Equation (3)

$$
\underbrace{\frac{\partial W}{\partial T}}_{\begin{array}{c}
\text { Rate of change of } \\
\text { surface water }
\end{array}}=\underbrace{A}_{R_{\text {ainfall }}}-\underbrace{L W}_{\begin{array}{c}
\text { water loss due } \\
\text { to evaporation }
\end{array}}-\underbrace{J W\left(\frac{P+s_{2} N_{0}}{P+s_{2}}\right)}_{\begin{array}{c}
\text { water infiltration } \\
\text { into the soil }
\end{array}}+\left\{[\underbrace{V \frac{\partial W}{\partial X}}_{\begin{array}{c}
\text { water movement at } \\
\text { uniform speed }
\end{array}}] \text { or }[\underbrace{D_{W}\left(\frac{\partial^{2} W}{\partial X^{2}}+\frac{\partial^{2} W}{\partial Y^{2}}\right)}_{\text {surface water movement }}]\right\}
$$

\subsubsection{Soil Water Dynamics}

Soil water at a particular position and time would involve infiltration into the soil from surface water, what may be taken up by plants growing at that particular position and time, the reduction that may be experienced due to evaporation and drainage, or flow to other parts. The soil water dynamics is therefore controlled by infiltration into the

$$
\text { Soil Water Loss by plant uptake }=J \times \frac{N(x, y, t)}{N(x, y, t)+s_{1}} \times P(x, y, t)
$$

where $J$ is as defined earlier and $s_{1}$ is a half-saturation constant. When the expression on the right-hand side of Equation (4) is substituted for soil water loss by plant uptake, the soil water dynamics of the proposed model in this paper is represented as in Equation (5)

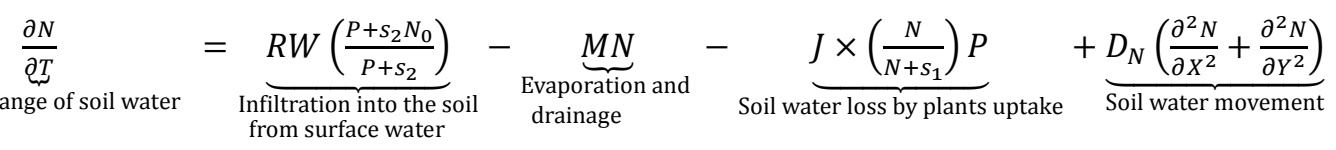

\subsubsection{Plant Biomass Dynamics}

The plant biomass dynamics of the proposed model of this paper compares with Biomass equation in Klausmeier's model but with slight modification. The modification to the Klausmeier [31] model in relation to plant biomass dynamics is the plant growth function $\beta$ which was introduced as an improvement factor. The plant biomass dynamics of this study is therefore controlled by soil water uptake by plants leading to plant growth, plant loss as a result of densityindependent mortality and maintenance, and plant dispersal.
This is represented by Equation (6).

$\frac{\partial P}{\partial T}=[$ Plant Growth $]+[$ Plant Loss $]+[$ Plant Dispersal $](6)$

It is assumed that plant growth increases linearly with soil water uptake. This is at its maximum when the availability of soil water permits maximum specific soil water uptake [35]. The Li et al. [32], growth model was introduced into the growth component of the plant biomass dynamics as $\beta$. This is to determine the dynamics of the model at different levels of $\beta$. The plant growth at a particular position and time is 
therefore represented by Equation (7)

$$
\text { Plant Growth at a Particular Point and Time }=(\beta+J) \times\left(\frac{N}{N+s_{1}}\right) P
$$

where $J$ is the specific plant growth with $\beta$ modelled as in Li et al. [32] growth model for comprehensive analysis. Plant population (biomass) density may be lost (decrease) through natural mortality $(U)$ and be defined as in Equation (8)

$$
\text { Plant Loss at a Particular Point and Time }=U \times P
$$

Plant movement, either through seed dispersal or any other form is given by the diffusion term indicated by Equation (9)

$$
\text { Plant Dispersal }=D_{P}\left(\frac{\partial^{2} P}{\partial X^{2}}+\frac{\partial^{2} P}{\partial Y^{2}}\right)
$$

When Equations (7), (8) and (9) are substituted into Equation (6) for plant growth, plant loss and plant dispersal respectively in the plant population dynamics relation given by Equation (6), one obtains Equation (10).

$$
\underbrace{\frac{\partial P}{\partial T}}_{\text {Rate of change of plant density }}=\underbrace{(J+\beta) \times\left(\frac{N}{N+s_{1}}\right) P}_{\text {Soil water uptake by plants/growth }}-\underbrace{U P}_{\begin{array}{c}
\text { Plant loss as a result } \\
\text { of mortality }
\end{array}}+\underbrace{D_{P}\left(\frac{\partial^{2} P}{\partial X^{2}}+\frac{\partial^{2} P}{\partial Y^{2}}\right)}_{\text {Plant dispersal }}
$$

The plant growth function, $\beta$ which was introduced into the model as an improvement factor is modelled by using $\mathrm{Li}$ et al. [32] model for crop growth process under the multienvironment external force action through continuous-time Markov process. This involves synthesizing the combined effects of the multiple resources (light, water, temperature and nutrients) and defined as in Equation (11)

$$
\beta=\frac{1-F_{1} N}{F_{2}+F_{3} N}
$$

where $F_{1}, \quad F_{2}$ and $F_{3}$ are three aggregate parameters, and are defined respectively by the Equations (12), (13) and (14)

$$
\begin{gathered}
F_{1}=\frac{\alpha_{6}\left(\lambda_{21}+\lambda_{23}\right)}{\lambda_{12} \lambda_{23}} \\
F_{2}=\frac{\left(\lambda_{21}+\lambda_{23}\right) \lambda_{61}}{\lambda_{12} \lambda_{23} \lambda_{61}}+\frac{\lambda_{12} \lambda_{61}}{\lambda_{12} \lambda_{23} \lambda_{61}} \\
+\frac{\lambda_{45} \lambda_{51}+\lambda_{34} \lambda_{51}+\lambda_{34} \lambda_{45}}{\lambda_{34} \lambda_{45} \lambda_{51}}
\end{gathered}
$$

or further,

$$
\begin{gathered}
F_{2}=\frac{\lambda_{21}}{\lambda_{12} \lambda_{23}}+\frac{1}{\lambda_{12}}+\frac{1}{\lambda_{23}}+\frac{1}{\lambda_{34}}+\frac{1}{\lambda_{45}}+\frac{1}{\lambda_{51}} \\
F_{3}=\frac{\alpha_{6}\left(\lambda_{21}+\lambda_{23}\right)}{\lambda_{12} \lambda_{23}} * \frac{1}{\lambda_{61}}=\frac{F_{1}}{\lambda_{61}}
\end{gathered}
$$

where $\lambda_{i j}$ are state transition rates and are considered as parameters of interest. These parameters are however restricted by the input of resources such as light, temperature, water and soil nutrients. Each of these transition rates are considered to be proportional to each resource. Thus, the transition rates are related to the resources as indicated in Equation (15)

$$
\lambda_{12}=\alpha_{1} I, \quad \lambda_{23}=\alpha_{2} T, \quad \lambda_{34}=\alpha_{3} H \text { and } \lambda_{45}=\alpha_{4} N
$$

where $I, T, H$ and $N$ represent the measure indices of light, temperature, water and soil nutrients, respectively. The $\alpha_{1}$, $\alpha_{2}, \alpha_{3}$ and $\alpha_{4}$ are the utilization coefficients of the corresponding resource. Substituting Equation (15) into (12),
(13) and (14) for $F_{1}, \quad F_{2}$ and $F_{3}$, respectively, as defined by Li et al. [32], one obtains Equations (16), (17) and (18).

$$
\begin{gathered}
F_{1}=\frac{\alpha_{6}\left(\lambda_{21}+\alpha_{2} T\right)}{\alpha_{1} \alpha_{2} I T} \\
F_{2}=\frac{\left(\lambda_{21}+\alpha_{2} T\right) \lambda_{61}}{\alpha_{1} I \alpha_{2} T \lambda_{61}}+\frac{\alpha_{1} I \lambda_{61}}{\alpha_{1} I \alpha_{2} T \lambda_{61}} \\
+\frac{\alpha_{4} N \lambda_{51}+\alpha_{3} H \lambda_{51}+\alpha_{3} H \alpha_{4} N}{\alpha_{3} H \alpha_{4} N \lambda_{51}}
\end{gathered}
$$

or further,

$$
\begin{gathered}
F_{2}=\frac{\lambda_{21}}{\alpha_{1} \alpha_{2} I T}+\frac{1}{\alpha_{1} I}+\frac{1}{\alpha_{2} T}+\frac{1}{\alpha_{3} H}+\frac{1}{\alpha_{4} N}+\frac{1}{\lambda_{51}} \\
F_{3}=\frac{\alpha_{6}\left(\lambda_{21}+\alpha_{2} T\right)}{\alpha_{1} \alpha_{2} I T} * \frac{1}{\lambda_{61}}=\frac{F_{1}}{\lambda_{61}}
\end{gathered}
$$

\subsection{Assumptions of the Model}

The proposed model factored into it four assumptions as follows:

(i) The descriptive variable of vegetation increase during vegetation growth is proportional to the surface water infiltration into the soil together with the contribution from multi environment external force action;

(ii) During rain showers of at least some considerable length, a steady state develops between rainfall, surface water motion, and water infiltration. This steady state is calculated from $\frac{[\partial W(x, y, t)]}{\partial T}=0$. Though, rain showers are discrete events, for the sake of model analysis, it is assumed that water infiltration rate is at steady state. This is to say that, water infiltration is a continuous water supply to the system at a position in space.

(iii) The per capita rate of water uptake is proportional to increase in plant population (biomass) density, reflecting the positive correlation between infiltration rate and plant population (biomass) density on the basis that water is the limiting resource.

(iv) Stationary assumption: Changes in surface water terms 
occur so rapidly in comparison to the plant population (biomass) density and soil water dynamics. This allows the surface water dynamics to be approximated as stationary during plant population (biomass) growth.

\subsubsection{The Proposed Model}

The proposed model is a system which consist of three nonlinear partial differential equations for surface water balance (W), Soil water balance (N) and Plant biomass variable $(\mathrm{P})$. The dimensional form relates to a situation where the surface water dynamics incorporates the flow due to pressure differences into a single parameter $D_{W}$, such that the surface water dynamics can be described by the term $D_{W}\left(\frac{\partial^{2} W}{\partial X^{2}+\frac{\partial^{2} W}{\partial Y^{2}}}\right)$. This system of equations is indicated as Equation (19).

$$
\begin{aligned}
& \underbrace{\frac{\partial W}{\partial T}}_{\text {Rate of change of surface water }}=\underbrace{A}_{\text {Rainfall }}-\underbrace{L W}_{\begin{array}{c}
\text { water loss due to } \\
\text { evaporation }
\end{array}}-\underbrace{R W\left(\frac{P+s_{2} N_{0}}{P+s_{2}}\right)}_{\begin{array}{c}
\text { surface water infiltration } \\
\text { into the soil }
\end{array}}+\underbrace{D_{W}\left(\frac{\partial^{2} W}{\partial X^{2}}+\frac{\partial^{2} W}{\partial Y^{2}}\right)}_{\text {Surface water movements }}
\end{aligned}
$$

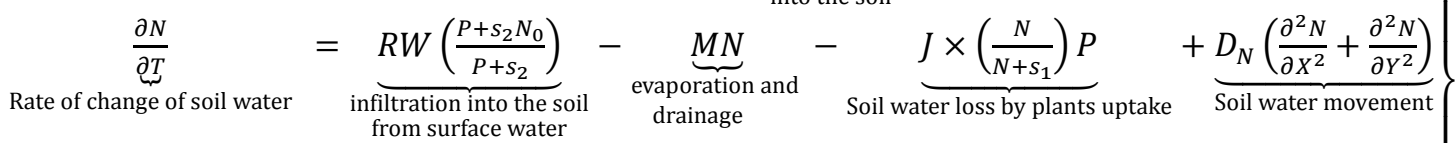

$$
\begin{aligned}
& \underbrace{\frac{\partial P}{\partial T}}_{\text {ge of plant density }}=\underbrace{(\beta+J) \times\left(\frac{N}{N+s_{1}}\right) P}_{\begin{array}{c}
\text { soil water uptake by } \\
\text { plants / growth }
\end{array}}-\underbrace{U P}_{\begin{array}{c}
\text { Plant loss as a result } \\
\text { of mortality }
\end{array}}+\underbrace{D_{P}\left(\frac{\partial^{2} P}{\partial X^{2}}+\frac{\partial^{2} P}{\partial Y^{2}}\right)}_{\text {plant dispersal }}
\end{aligned}
$$

where $T$ is the time and $(X, Y)$ represent the spatial domain.

\subsubsection{Non-depersonalization of the Model}

The dimensionless form of the proposed model is given by Equation (20)

$$
\left.\begin{array}{l}
\frac{\partial w}{\partial t}=a-l w-r\left(\frac{p+N_{0}}{p+1}\right) w+\left(\frac{\partial^{2} w}{\partial x^{2}}+\frac{\partial^{2} w}{\partial y^{2}}\right) \\
\frac{\partial n}{\partial t}=\left(\frac{p+N_{0}}{p+1}\right) w-m n-g\left(\frac{n}{n+1}\right) p+D_{N W}\left(\frac{\partial^{2} n}{\partial x^{2}}+\frac{\partial^{2} n}{\partial y^{2}}\right) \\
\frac{\partial p}{\partial t}=\left(\frac{n}{n+1}\right) p-u p+D_{P W}\left(\frac{\partial^{2} p}{\partial x^{2}}+\frac{\partial^{2} p}{\partial y^{2}}\right)
\end{array}\right\}
$$

with its dimensionless parameters and variables indicated by Equation (21).

\begin{tabular}{|c|c|c|c|}
\hline Dimensional Parameters with meanings & Value & Dimensionless Parameter & Value \\
\hline$A$ : Mean water supply or mean rainfall & Varied & $a=\frac{A R}{(J+\beta)^{2} s_{1}}$ & Varied \\
\hline$L:$ Rate of evaporation of surface water & 0.15 & $l=\frac{L}{(J+\beta)}$ & Varied \\
\hline$R:$ Rate of infiltration & 0.05 & $g=\frac{J s_{2}}{(J+\beta) s_{1}}$ & Varied \\
\hline$M$ : Rate of evaporation and drainage of soil water & 0.005 & $m=\frac{M}{(J+\beta)}$ & Varied \\
\hline$D_{N}$ : Diffusion coefficient of soil water & 0.1 & $r=\frac{R}{J+\beta}$ & Varied \\
\hline$D_{P}$ : Dispersal coefficient of plant density & 20 & $u=\frac{U}{J+\beta}$ & Varied \\
\hline$D_{W}:$ Diffusion coefficient of surface water & 0.4 & $v=\left(\frac{1}{\{J+\beta\} D_{N}}\right)^{\frac{1}{2}} V$ & Varied \\
\hline $\begin{array}{l}U: \text { Plant mortality rate } \\
V: \text { Speed of flow of water downhill }\end{array}$ & $\begin{array}{l}0.10 \\
4\end{array}$ & & \\
\hline$J$ : Yield of plant density per unit of soil water consumed & 0.35 & $D_{N W}=\frac{D_{N}}{D_{W}}$ & Varied \\
\hline
\end{tabular}

$$
\begin{aligned}
& \left.a=\frac{A R}{(\beta+J)^{2} s_{1}}, \quad l=\frac{L}{(\beta+J)}, \quad r=\frac{R}{(\beta+J)}, \quad m=\frac{M}{(\beta+J)}, \quad g=\frac{J s_{2}}{(\beta+J) s_{1}},\right) \\
& u=\frac{U}{(\beta+J)}, y=\left(\frac{(\beta+J)}{D_{W}}\right)^{\frac{1}{2}} Y, x=\left(\frac{(\beta+J)}{D_{W}}\right)^{\frac{1}{2}} X, D_{P W}=\frac{D_{P}}{D_{W}}, \\
& \left.w=\frac{W R}{(\beta+J) s_{1}}, \quad D_{N W}=\frac{D_{N}}{D_{W}}, \quad t=(\beta+J) T, \quad n=\frac{N}{s_{1}}, \quad p=\frac{P}{s_{2}} \quad\right)
\end{aligned}
$$

Table 1 gives the meaning of the dimensional and dimensionless model parameters and their values used in the simulations

Table 1. Dimensional and Dimensionless Parameters used in the Model Simulations. 


\begin{tabular}{|c|c|c|c|}
\hline Dimensional Parameters with meanings & Value & Dimensionless Parameter & Value \\
\hline$\beta$ : Plant growth function that represent a multi-environment force action & Varied & $D_{P N}=\frac{D_{P}}{D_{N}}$ & Varied \\
\hline$s_{1}:$ Half-saturation constant of specific plant growth and water uptake & 0.03 & $D_{P W}=\frac{D_{P}}{D_{W}}$ & Varied \\
\hline $\begin{array}{l}S_{2}: \text { Rate at which infiltration increases with specific plant density } \\
N_{0}: \text { Minimum water infiltration in the absence of plant }\end{array}$ & $\begin{array}{l}0.03 \\
0.03\end{array}$ & & \\
\hline
\end{tabular}

\subsection{Conditions for Pattern Formation}

The first step in the investigation of the pattern-forming potential of the system of Equations (20) is to determine the spatially homogeneous steady states of the system. If the steady state is stable, then it implies that pattern formation is possible. Estimating the steady state conditions, the following two steady states $E_{1}^{*}=\left(w^{*}, n^{*}, 0\right)$ and $E_{2}^{*}=$ $\left(w^{*}, n^{*}, p^{*}\right)$ were obtained. $E_{1}^{*}$ which is the trivial equilibrium point, biologically represents a trivial situation and was obtained as shown in Equation (22):

$$
E_{1}^{*}=\left[w^{*}=\frac{a}{r N_{0}+l}, \quad n^{*}=\frac{a N_{0}}{m\left(r N_{0}+l\right)}, \quad p^{*}=0\right]
$$

In similar manner, $E_{2}^{*}$ which is the non-trivial equilibrium situation and ecologically plausible admits the equilibrium point provided for as in Equation (23)

$$
E_{2}^{*}=\left[w=\frac{a\left(p_{s}+1\right)}{l\left(p_{s}+1\right)+r\left(p_{s}+N_{0}\right)}, n=\frac{u}{1-u}, p=\frac{a-l w-r m u}{g r u}\right]
$$

The next step is to linearize the system of the nonlinear model at the steady states. This was done in order to understand the behavior of the system at the equilibrium points.

A necessary and sufficient conditions for linear stability are that, the trace of the associated Jacobian should be less than zero and its determinant should be positive. Hence, for pattern formation to occur, instability is required. Thus, for pattern formation, one ascribes to situations where $\operatorname{trJ}>0$ and Det $J<0$ or either one of them is true for the system to be unstable.

\section{Analysis and Simulations of the Model}

Simulations of the model were obtained based on the distribution of the vegetation at different values of the growth parameter $\beta$; and the validation of the numerical algorithm.

\subsection{Numerical Simulations of Model}

The numerical simulation of the system of Equation (20) was carried out using a set of parameter values to illustrate vegetation pattern at different values of the growth parameter $\beta$. Most of the parameter values used for the simulations were obtained from literature as observed from Table 2.

From the aggregate parameter formulas given by Equations (16), (17) and (18), and the data in Table 2, the aggregate parameter values under each water-condition and fertility level are represented as shown in Table 3.

\subsection{Distribution of the Vegetation Patterns at Different $\beta-$ values}

The spatial patterns associated with the different fertility levels for the different water conditions for the proposed model with the parameter set of values in Table 1 were numerically simulated. A direct numerical simulation of system Equation (19) was carried out with different fertility levels under different water conditions. From the set of values in Tables 2 and 3, the vegetation patterns under each water condition and fertility level were obtained as follows.

\subsubsection{Distribution of Vegetation Patterns for Different $\beta$-values Under Rich Water Condition}

The state transition parameters, utilisation coefficients and measure indices for Control fertility, Lower fertility, Middle fertility and Higher fertility under Rich water condition are given in Table 4.

\begin{tabular}{|c|c|c|c|c|c|c|c|c|c|c|c|c|}
\hline \multirow{2}{*}{ Parameters } & \multicolumn{4}{|c|}{ Rich water } & \multicolumn{4}{|c|}{ Average water } & \multicolumn{4}{|c|}{ Aridity } \\
\hline & CK & $\mathbf{L}$ & M & H & CK & $\mathbf{L}$ & M & $\mathbf{H}$ & CK & $\mathbf{L}$ & M & H \\
\hline I & 1.00 & 1.00 & 1.00 & 1.00 & 1.00 & 1.00 & 1.00 & 1.00 & 1.00 & 1.00 & 1.00 & 1.00 \\
\hline $\mathrm{T}$ & 0.766 & 0.766 & 0.766 & 0.766 & 0.766 & 0.766 & 0.766 & 0.766 & 0.766 & 0.766 & 0.766 & 0.766 \\
\hline $\mathrm{H}$ & 0.875 & 0.875 & 0.875 & 0.875 & 0.75 & 0.75 & 0.75 & 0.75 & 0.588 & 0.588 & 0.588 & 0.588 \\
\hline $\mathrm{N}$ & 0.690 & 0.793 & 0.896 & 1.000 & 0.690 & 0.793 & 0.089 & 1.000 & 0.690 & 0.793 & 0.896 & 1.000 \\
\hline$\alpha_{1}$ & 0.589 & 0.733 & 0.786 & 0.900 & 0.426 & 0.692 & 0.917 & 0.876 & 0.292 & 0.367 & 0.444 & 0.419 \\
\hline$\alpha_{2}$ & 0.662 & 0.662 & 0.662 & 0.662 & 0.662 & 0.662 & 0.662 & 0.662 & 0.662 & 0.662 & 0.662 & 0.662 \\
\hline$\alpha_{3}$ & 0.91 & 0.91 & 0.91 & 0.91 & 0.91 & 0.91 & 0.91 & 0910 & 0.90 & 0.90 & 0.90 & 0.90 \\
\hline$\alpha_{4}$ & 0.87 & 0.82 & 0.91 & 0.95 & 0.86 & 0.89 & 0.86 & 1.00 & 0.77 & 0.65 & 0.62 & 0.45 \\
\hline$\alpha_{6}$ & 0.076 & 0.084 & 0.071 & 0.071 & 0.127 & 0.118 & 0.092 & 0.092 & 0.122 & 0.131 & 0.100 & 0.096 \\
\hline$\lambda_{21}$ & 0.06 & 0.06 & 0.06 & 0.06 & 0.06 & 0.06 & 0.06 & 0.06 & 0.06 & 0.06 & 0.06 & 0.06 \\
\hline$\lambda_{51}$ & 4.5 & 4.5 & 4.5 & 4.5 & 4.5 & 4.5 & 4.5 & 4.5 & 4.5 & 4.5 & 4.5 & 4.5 \\
\hline$\lambda_{61}$ & 0.12 & 0.12 & 0.12 & 0.12 & 0.12 & 0.12 & 0.12 & 0.12 & 0.12 & 0.12 & 0.12 & 0.12 \\
\hline
\end{tabular}

Table 2. Values of State Transition Parameters, Utilisation Coefficients and Measure Indices for Different Levels of Fertility under Different Water Conditions.

Source: Li et al. [32] 
Table 3. Aggregate Parameters under each Water-Fertility Condition.

\begin{tabular}{lllll}
\hline \multirow{2}{*}{ Water Fertility } & & Aggregate Parameter & & $\boldsymbol{F}_{\mathbf{3}}$ \\
\cline { 3 - 5 } & & $\boldsymbol{F}_{\mathbf{1}}$ & 7.0147 & 1.2088 \\
\multirow{3}{*}{ Rich } & Control Fertility & 0.1451 & 6.2045 & 1.0642 \\
& Lower Fertility & 0.1277 & 5.7342 & 0.8383 \\
& Middle Fertility & 0.1006 & 5.1725 & 0.6655 \\
\multirow{4}{*}{ Average } & Higher Fertility & 0.0799 & 7.9698 & 2.7674 \\
& Control Fertility & 0.3321 & 6.3604 & 1.5891 \\
& Lower Fertility & 0.1907 & 5.7614 & 0.9340 \\
\multirow{4}{*}{ Aridity } & Middle Fertility & 0.1121 & 5.4301 & 0.9798 \\
& Higher Fertility & 0.1176 & 9.4369 & 3.8777 \\
& Control Fertility & 0.4653 & 8.4110 & 3.3164 \\
\hline
\end{tabular}

Table 4. State Transition Parameters, Utilisation Coefficients and Measure Indices for Control Fertility, Lower Fertility, Middle Fertility and Higher fertility under Rich Water Condition.

\begin{tabular}{|c|c|c|c|c|}
\hline Parameter & Control & Lower Fertility & Middle Fertility & Higher Fertility \\
\hline$I$ & 1.000 & 1.000 & 1.000 & 1.000 \\
\hline$T$ & 0.766 & 0.766 & 0.766 & 0.766 \\
\hline$H$ & 0.875 & 0.875 & 0.875 & 0.875 \\
\hline$\alpha_{1}$ & 0.733 & 0.733 & 0.786 & 0.990 \\
\hline$\alpha_{2}$ & 0.662 & 0.662 & 0.662 & 0.662 \\
\hline$\alpha_{3}$ & 0.910 & 0.910 & 0.910 & 0.910 \\
\hline$\alpha_{4}$ & 0.820 & 0.82 & 0.91 & 0.950 \\
\hline$\alpha_{6}$ & 0.0837 & 0.0837 & 0.0707 & 0.0707 \\
\hline$\lambda_{21}$ & 0.06 & 0.06 & 0.06 & 0.06 \\
\hline$\lambda_{51}$ & 4.5 & 4.5 & 4.5 & 4.5 \\
\hline$\lambda_{61}$ & 0.12 & 0.12 & 0.12 & 0.12 \\
\hline
\end{tabular}

From Table 4, the aggregate parameters for the evaluation of different $\beta$-values representing fertility levels under richwater condition is summarised in Table 5 .

Table 5. The Aggregate Parameters for Evaluation of Different $\beta$-Values Representing Fertility Levels under Rich-Water Condition.

\begin{tabular}{lllll}
\hline \multirow{2}{*}{ Water fertility } & \multicolumn{3}{l}{ Aggregate Parameter } \\
\cline { 2 - 5 } & Control fertility & $\boldsymbol{F}_{\mathbf{1}}$ & $\boldsymbol{F}_{\mathbf{2}}$ & $\boldsymbol{F}_{\mathbf{3}}$ \\
\hline \multirow{3}{*}{ Rich } & Lower fertility & 0.1451 & 7.0147 & 1.2088 \\
\multirow{2}{*}{ water } & Middle fertility & 0.1006 & 6.2045 & 1.0642 \\
& Higher fertility & 0.0799 & 5.1725 & 0.8383 \\
& & &
\end{tabular}

\subsubsection{Vegetation Pattern of Control Fertility Under Rich Water Condition}

The final simulated pattern of the vegetation with a $\beta$-value of 0.1146524577 for Control fertility under rich water condition is shown in Figure 1.

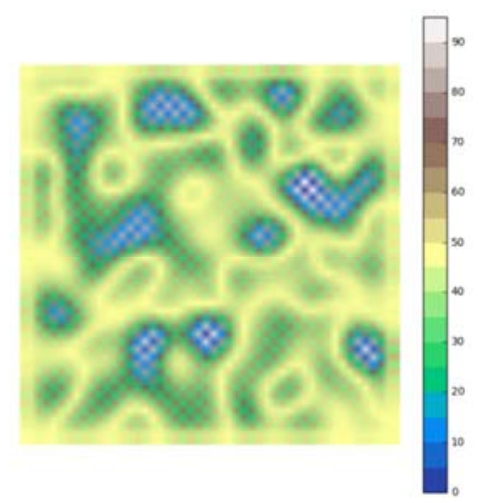

Figure 1. Final Vegetation Pattern of Control Fertility under Rich Water Condition with a $\beta$-value of 0.1146524577.

\subsubsection{Vegetation Pattern of Lower Fertility Under Rich Water Condition}

The final simulated pattern of the vegetation with a $\beta$-value of 0.1275087323 for lower fertility under rich water condition is shown in Figure 2.

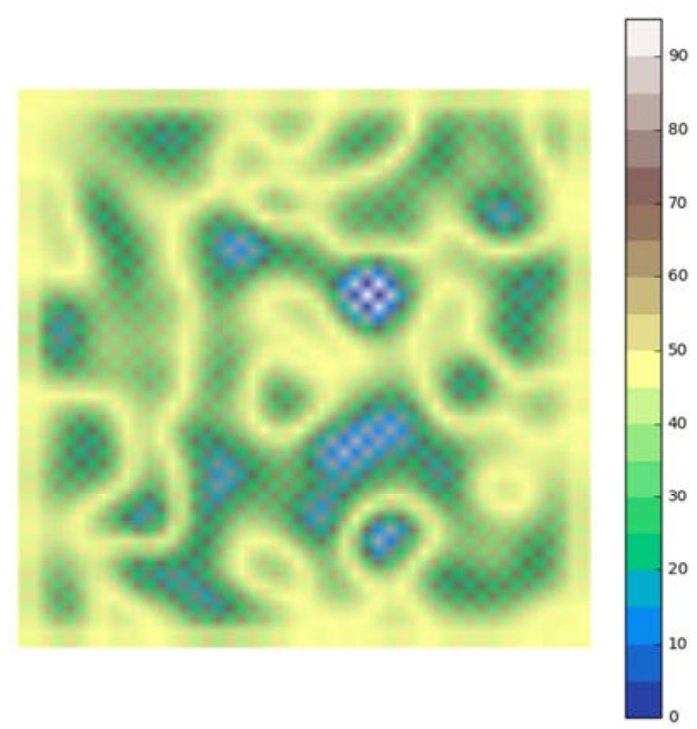

Figure 2. Final Vegetation Pattern of Lower Fertility under Rich Water Condition with a $\beta-$ value of 0.1275087323 .

\subsubsection{Vegetation Pattern of Middle Fertility Under Rich Water Condition}

The final simulated pattern of the vegetation with a $\beta$-value of 0.1402957524 for middle fertility under rich water condition as shown in Figure 3. 


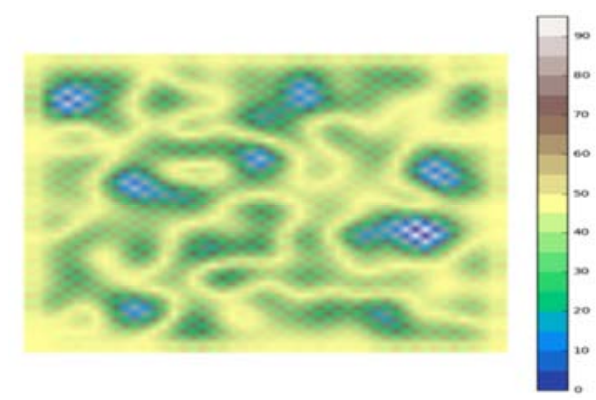

Figure 3. Final Vegetation Pattern of Middle Fertility under Rich Water Condition with a $\beta$-value of 0.1402957524

\subsubsection{Vegetation Pattern of Higher Fertility Under Rich Water Condition}

The final simulated patterns of the vegetation with a $\beta$-value of 0.1576053443 for higher fertility under rich water condition is indicated in Figure 4.

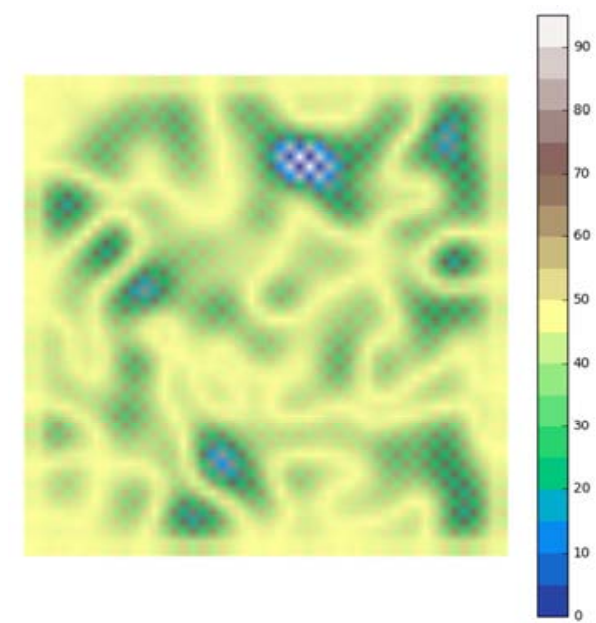

Figure 4. Final Vegetation Pattern of Higher Fertility under Rich Water Condition with a $\beta$-value of 0.1576053443 .

The vegetation patterns for various $\beta$-values representing control fertility, lower fertility, middle fertility and higher fertility under rich water condition were compared as shown in Figure 5.

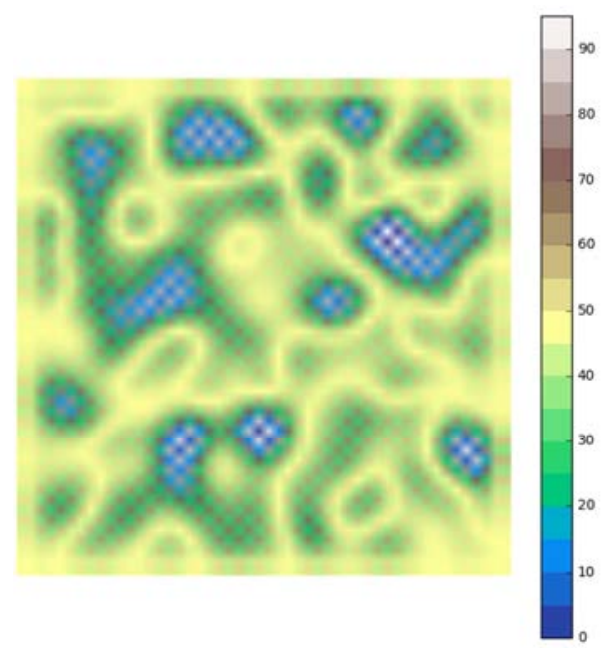

(a) Control Fertility

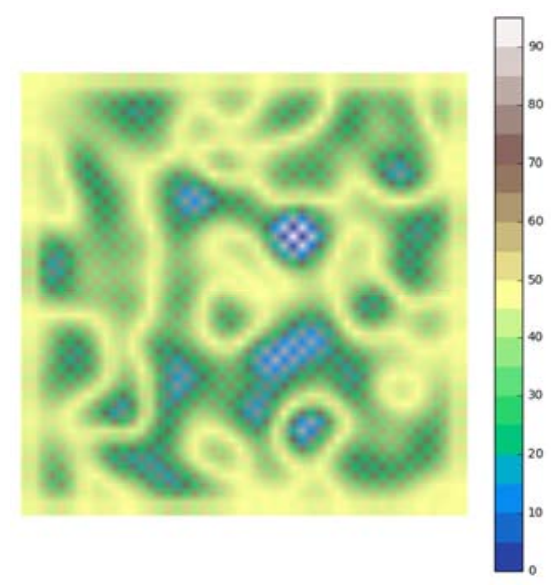

(b) Lower Fertility

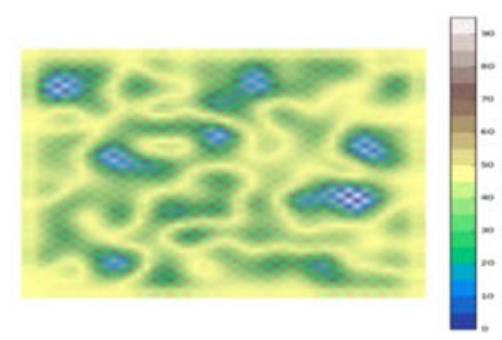

(c) Middle Fertility

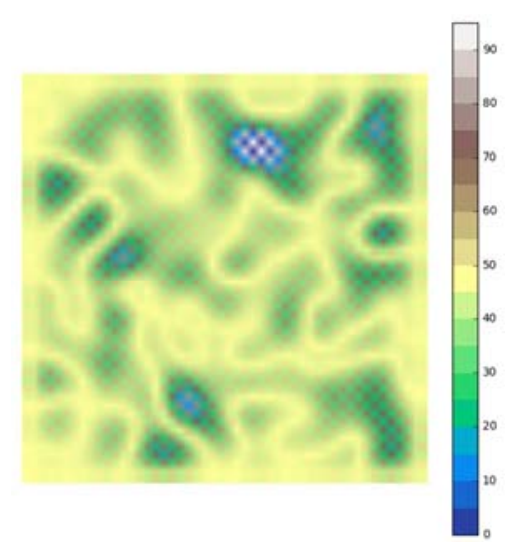

(d) Higher Fertility

Figure 5. Spatial Patterns for Control Fertility, Lower Fertility, Middle Fertility and Higher Fertility Levels of the Soil under Rich Water Condition.

The spatial patterns generated by the proposed model are revealed in a two-dimensional domain of a numerical simulations. Different levels of soil fertility namely control fertility, lower fertility, middle fertility and higher fertility based on their state transition parameters, utilisation coefficients and measure indices determined under Rich water condition were then compared.

The effects of changes in the fertility levels on the patterns formed by the vegetation under Rich water condition were examined. The $\beta$-value representing these fertility levels were computed analytically based on the state transition parameters, utilisation coefficients and measure indices. Thus, the effects of $\beta$ on the vegetation as predicted by the model Equation (19) were shown. 
For a $\beta$-value of 0.1146524577 representing the Control fertility under rich water condition, the vegetation shows a pattern with quite a number of patches of bare or almost bare land as shown in Figure 5a. The number of patches of bare or almost bare land formed by the vegetation reduced and the area covered by these patches somehow dwindled for a $\beta$-value of 0.1275087323 representing lower fertility. This is as shown in figure $5 \mathrm{~b}$. Though the number of patches of bare or almost bare land seems numerous in the case of 0.1402957524 for middle fertility, the intensity of the vegetation is high as compared to that of lower fertility and the corresponding patches of bare land are narrower. This can best be looked at based on the colour bar associated with the vegetation pattern. This is equally represented by figure $5 \mathrm{c}$. When the $\beta$-value is at
0.1576053443 representing higher fertility, patches of bare or almost bare land were barely absent compared to other fertility levels represented by figures $5 \mathrm{a}, 5 \mathrm{~b}$ and $5 \mathrm{c}$. However, the patches of bare or almost bare land is not wholly absent. Again, the colour bar shows that the intensity of the vegetation is very high compared to all the others. This is shown by Figure $5 \mathrm{~d}$.

\subsection{Distribution of Vegetation Patterns for Different $\beta$-Values Under Average Water Condition}

Similarly, the state transition parameters, utilisation coefficients and measure indices for Control fertility, lower fertility, middle fertility and higher fertility under Average water condition are indicated in Table 6.

Table 6. State Transition Parameters, Utilisation Coefficients and Measure Indices for Control Fertility, Lower Fertility, Middle Fertility and Higher Fertility under Average Water Condition.

\begin{tabular}{cllll}
\hline Parameter & Control & Lower Fertility & Middle Fertility & Higher Fertility \\
\hline$I$ & 1.000 & 1.000 & 1.000 & 0.766 \\
$T$ & 0.766 & 0.766 & 0.750 & 0.766 \\
$H$ & 0.750 & 0.750 & 0.896 & 0.750 \\
$N$ & 0.690 & 0.793 & 0.917 & 1.000 \\
$\alpha_{1}$ & 0.426 & 0.692 & 0.662 & 0.876 \\
$\alpha_{2}$ & 0.662 & 0.662 & 0.910 & 0.662 \\
$\alpha_{3}$ & 0.910 & 0.910 & 0.86 & 0.910 \\
$\alpha_{4}$ & 0.860 & 0.890 & 0.0919 & 1.000 \\
$\alpha_{6}$ & 0.1265 & 0.1180 & 0.06 & 0.0921 \\
$\lambda_{21}$ & 0.06 & 0.06 & 4.5 & 0.06 \\
$\lambda_{51}$ & 4.5 & 4.5 & 0.12 & 4.5 \\
$\lambda_{61}$ & 0.12 & 0.12 & & 0.12 \\
\hline
\end{tabular}

From Table 6, the aggregate parameters for the evaluation of different $\beta$-values under Average-water condition for Control fertility, Lower fertility, Middle fertility and Higher fertility are summarised in Table 7.

Table 7. Aggregate Parameters for the Evaluation of Different Values under Average Water Condition.

\begin{tabular}{lllll}
\hline \multirow{2}{*}{ Water fertility } & \multicolumn{3}{l}{ Aggregate Parameter } \\
\cline { 3 - 5 } & & $\boldsymbol{F}_{\mathbf{1}}$ & $\boldsymbol{F}_{\mathbf{2}}$ & $\boldsymbol{F}_{\mathbf{3}}$ \\
\hline \multirow{3}{*}{ Average } & Control fertility & 0.3321 & 7.9698 & 2.7674 \\
water & Lower fertility & 0.1907 & 6.3604 & 1.5891 \\
& Middle fertility & 0.1121 & 5.7614 & 0.9340 \\
& Higher fertility & 0.1176 & 5.4301 & 0.9798 \\
\hline
\end{tabular}

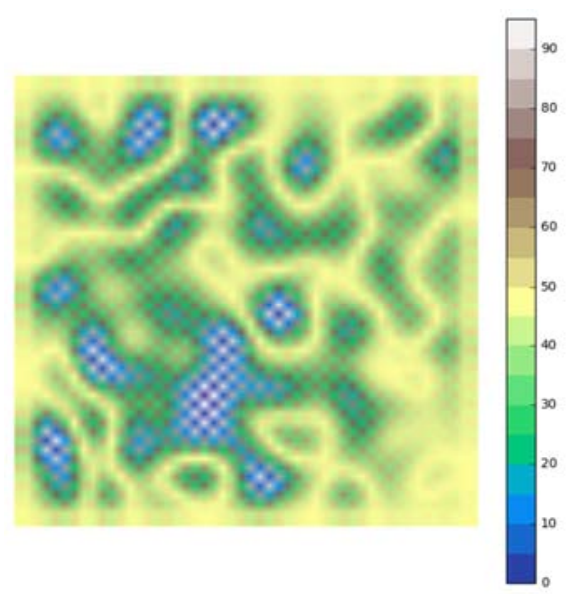

Figure 6. Vegetation Pattern of Control Fertility under Average Water with a $\beta$-Value of 0.0780268371 .

\subsubsection{Vegetation Pattern of Control Fertility Under Average Water Condition}

The final simulated pattern of the vegetation with a $\beta$-value of 0.0780268371 for Control fertility under average water condition is shown in Figure 6.

\subsubsection{Vegetation Pattern for Lower Fertility Under Average Water Condition}

The final simulated pattern of the vegetation with a $\beta$-value of 0.1113796509 for lower fertility under average water condition is indicated in Figure 7.

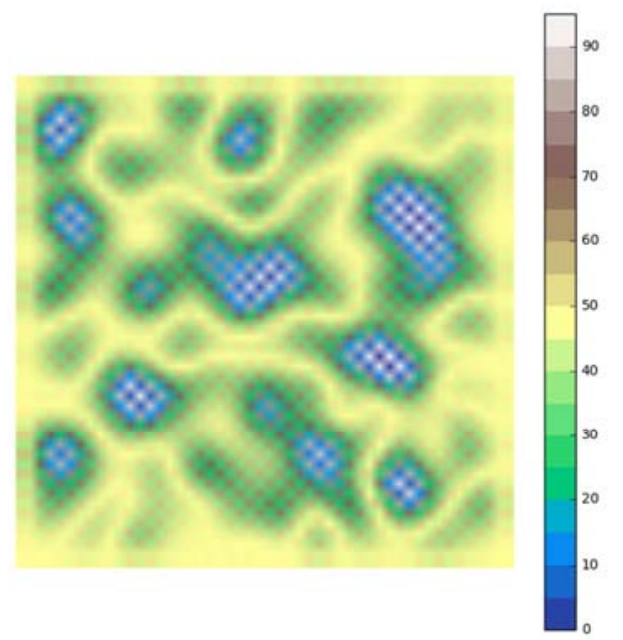

Figure 7. Final Vegetation Pattern of Lower Fertility under Average Water with a $\beta$-Value of $\beta=0.1113796509$. 


\subsubsection{Vegetation Pattern of Middle Fertility Under Average \\ Water}

The final simulated growth pattern of the vegetation with a $\beta$ - value of 0.1363325869 for middle fertility under average water condition is also shown in the Figure 8.

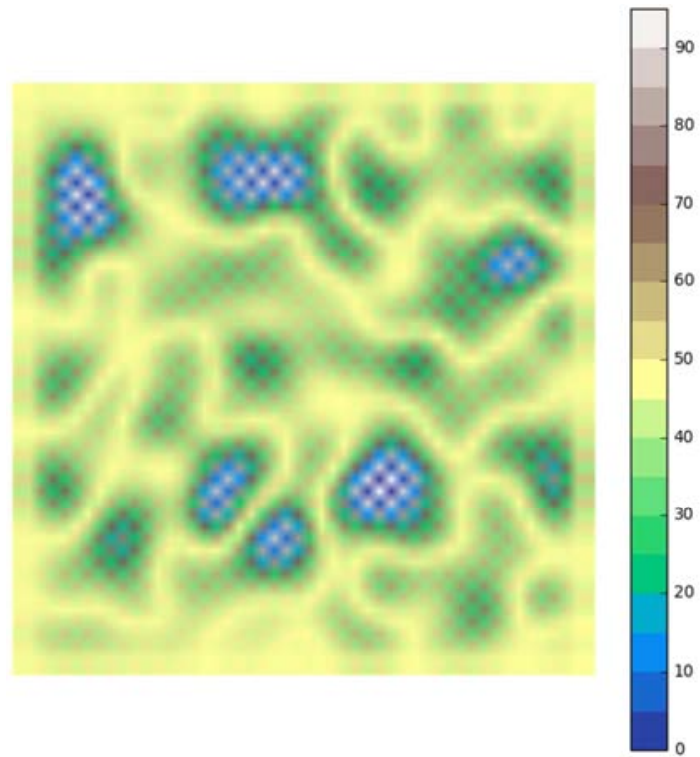

Figure 8. Final Vegetation Pattern of Middle Fertility under Average Water with a $\beta$-Value of 0.1363325869 .

\subsubsection{Vegetation Pattern of Higher Fertility Under Average Water Condition}

The final simulated growth patterns of the vegetation with a $\beta$-value of 0.137662054 for higher fertility under average water is indicated in Figure 9.

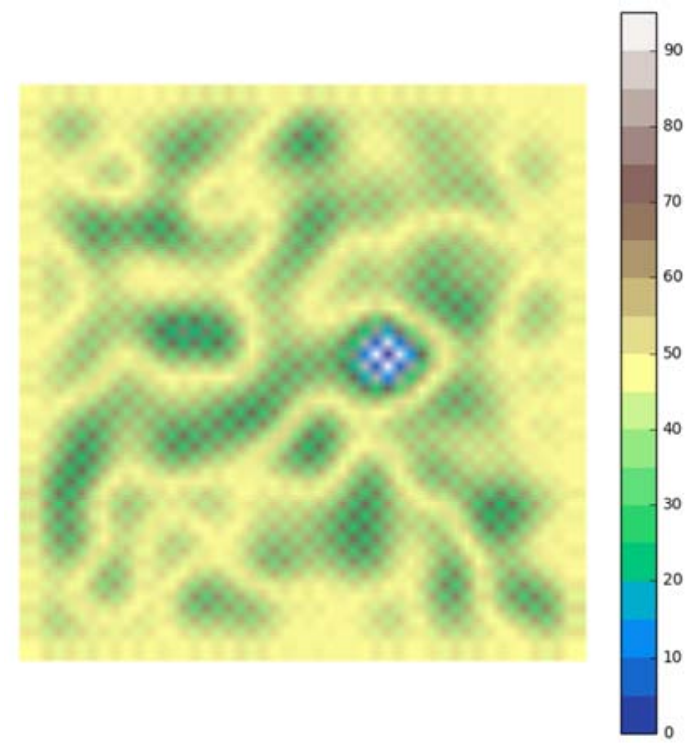

Figure 9. Final Vegetation Pattern of Higher Fertility under Average Water with a $\beta$ - Value of 0.137662054 .

The final stages for various $\beta$-values representing Control fertility, lower fertility, middle fertility and higher fertility under Average Water Condition were compared as shown in Figure 10
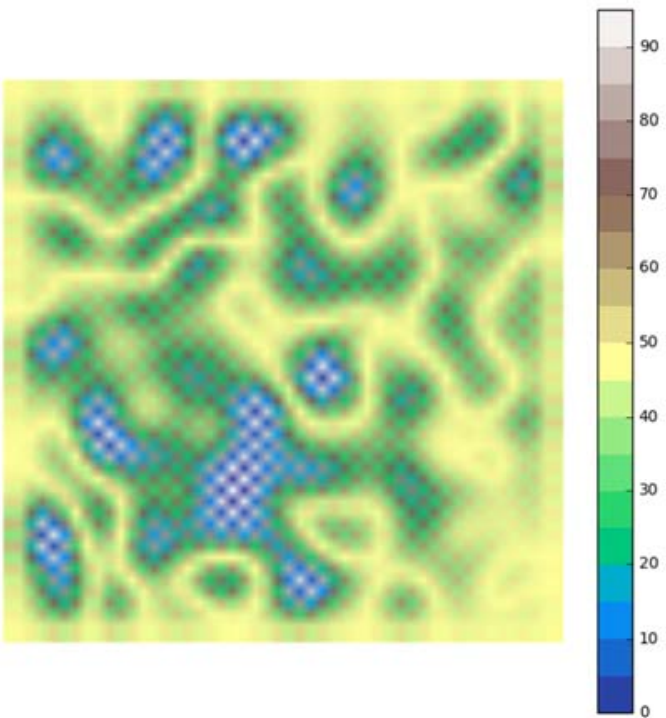

(a) Control Fertility

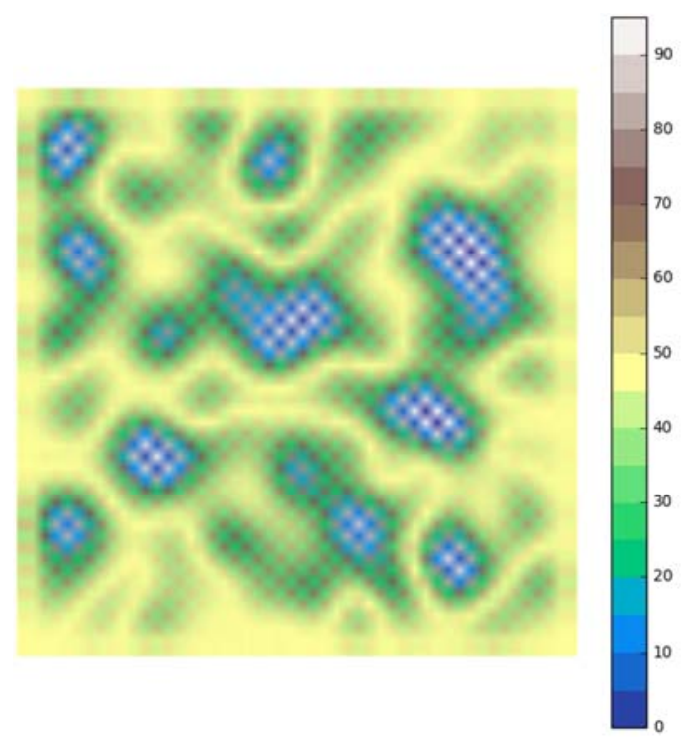

(b) Lower Fertility

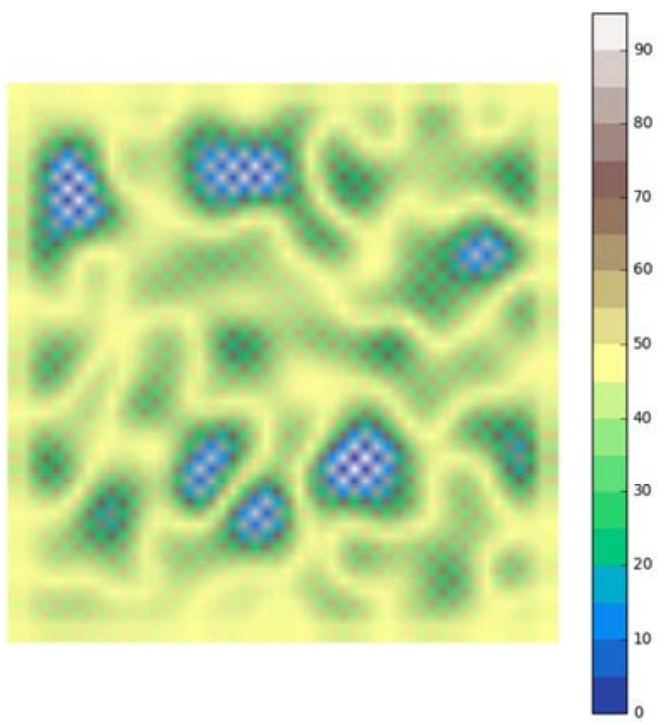

(c) Middle Fertility 


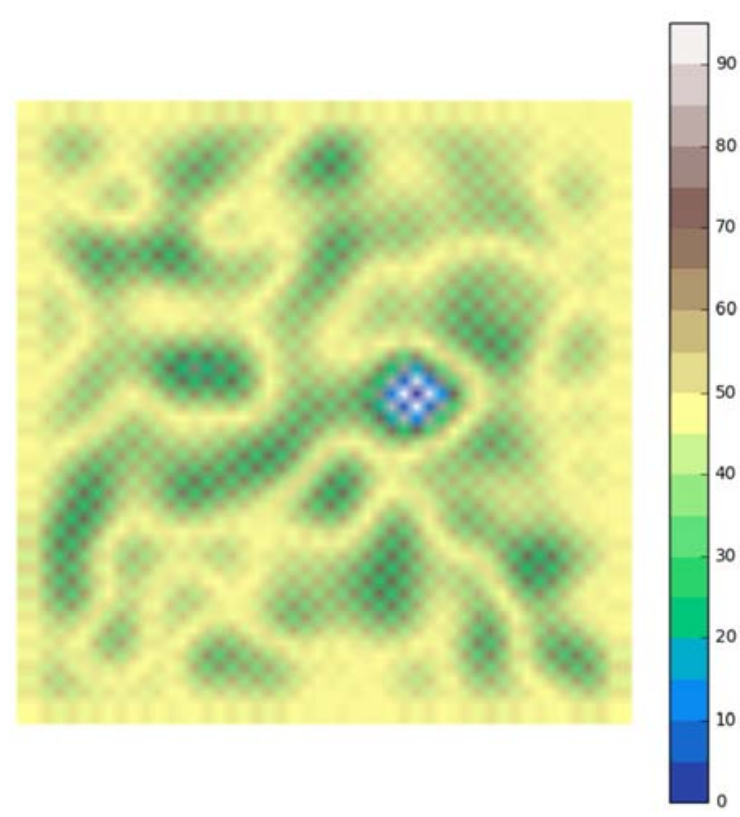

(d) Higher Fertility

Figure 10. Spatial Patterns for Control Fertility, Lower Fertility, Middle Fertility and Higher Fertility of the Soil under Average Water Condition.

The spatial patterns generated under different levels of soil fertility based on the state transition parameters, utilisation coefficients and measure indices were determined for Average water condition and then compared.

The effects of different fertility levels associated with the patterns formed by the vegetation under Average water condition were examined.

For $\beta$-value of 0.0780268371 representing the Control fertility under Average water condition, the vegetation shows a pattern with quite a number of patches of bare or almost bare land of which some are labyrinth in nature. These patches of bare land comparatively cover wider areas. This is shown in Figure 10a. Though the number of patches of bare or almost bare land formed by the vegetation under lower fertility appear to be more compared with the case of control fertility, the areas covered by these patches are somehow dwindled for $\beta=0.1113796509$ representing the lower fertility. This is shown in Figure 10b. There was a further drastic decrease in the number of patches of bare or almost bare land and a corresponding dwindling of these patches of bare land at $\beta=0.1363325869$ for middle fertility. This is equally represented by figure $10 \mathrm{c}$. When the $\beta$-value is at 0.137662054 representing higher fertility, patches of bare or almost bare land reduced considerably. The intensity of the patches of vegetation is quite high as compared to all the others. This is shown by Figure 10d.

\subsection{Distribution of Vegetation Patterns for Different $\beta$-Values Under Arid Condition}

In similar manner, the state transition parameters, utilisation coefficients and measure indices for Control fertility, lower fertility, middle fertility and higher fertility under Arid condition are given in Table 8.
Table 8. State Transition Parameters, Utilisation Coefficients and Measure Indices for Control Fertility, Lower Fertility, Middle Fertility and Higher fertility under Arid Environment.

\begin{tabular}{cllll}
\hline Parameter & Control & $\begin{array}{l}\text { Lower } \\
\text { Fertility }\end{array}$ & $\begin{array}{l}\text { Middle } \\
\text { Fertility }\end{array}$ & $\begin{array}{l}\text { Higher } \\
\text { Fertility }\end{array}$ \\
\hline$I$ & 1.000 & 1.000 & 1.000 & 1.000 \\
$T$ & 0.766 & 0.766 & 0.766 & 0.766 \\
$H$ & 0.588 & 0.588 & 0.588 & 0.588 \\
$N$ & 0.690 & 0.793 & 0.896 & 1.000 \\
$\alpha_{1}$ & 0.292 & 0.367 & 0.444 & 0.419 \\
$\alpha_{2}$ & 0.662 & 0.662 & 0.662 & 0.662 \\
$\alpha_{3}$ & 0.900 & 0.900 & 0.900 & 0.900 \\
$\alpha_{4}$ & 0.770 & 0.650 & 0.620 & 0.450 \\
$\alpha_{6}$ & 0.1215 & 0.1306 & 0.100 & 0.0964 \\
$\lambda_{21}$ & 0.06 & 0.06 & 0.06 & 0.06 \\
$\lambda_{51}$ & 4.5 & 4.5 & 4.5 & 4.5 \\
$\lambda_{61}$ & 0.12 & 0.12 & 0.12 & 0.12 \\
\hline
\end{tabular}

From Table 8, the aggregate parameters for the evaluation of different $\beta$-values for Control fertility, lower fertility, middle fertility and higher fertility under Arid condition are indicated in Table 9.

Table 9. The Aggregate Parameters for the Evaluation of Different Values under Arid Condition.

\begin{tabular}{lllll}
\hline \multirow{2}{*}{ Water fertility } & \multicolumn{3}{l}{ Aggregate Parameter } \\
\cline { 2 - 4 } & & $\boldsymbol{F}_{\mathbf{1}}$ & $\boldsymbol{F}_{\mathbf{2}}$ & $\boldsymbol{F}_{\mathbf{3}}$ \\
\hline \multirow{3}{*}{ Aridity } & Control fertility & 0.4653 & 9.4369 & 3.8777 \\
& Lower fertility & 0.3980 & 8.4110 & 3.3164 \\
& Middle fertility & 0.2519 & 7.6452 & 2.990 \\
& Higher fertility & 0.2573 & 8.3001 & 2.1441 \\
\hline
\end{tabular}

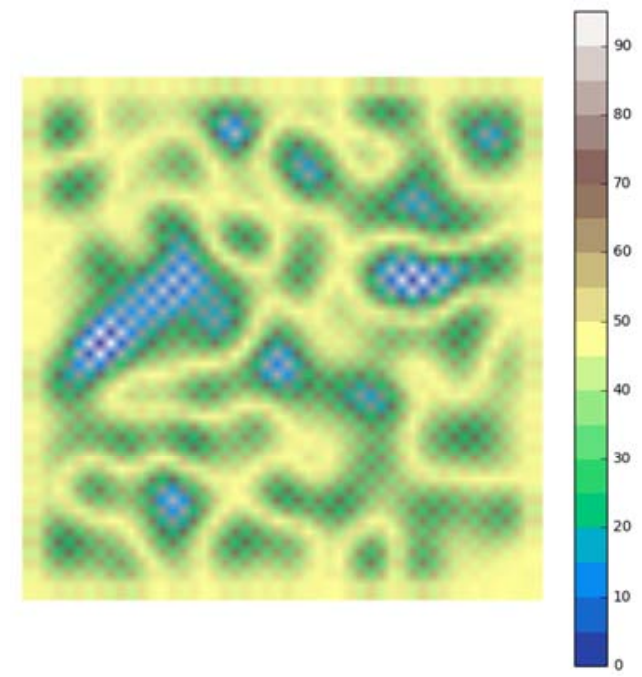

Figure 11. Final Vegetation Pattern of Control Fertility under Arid Water with a $\beta$-Value of 0.0560530255 .

\subsubsection{Vegetation Pattern of Control Fertility Under Arid Condition}

The final simulated growth pattern of the vegetation with a $\beta$-value of 0.0560530255 for Control fertility under arid condition is indicated in Figure 11.

\subsubsection{Vegetation Pattern of Lower Fertility Under Arid Condition}

The final simulated growth pattern of the vegetation with a $\beta$-value of 0.0619864031 for lower fertility under arid water is indicated in Figure 12. 


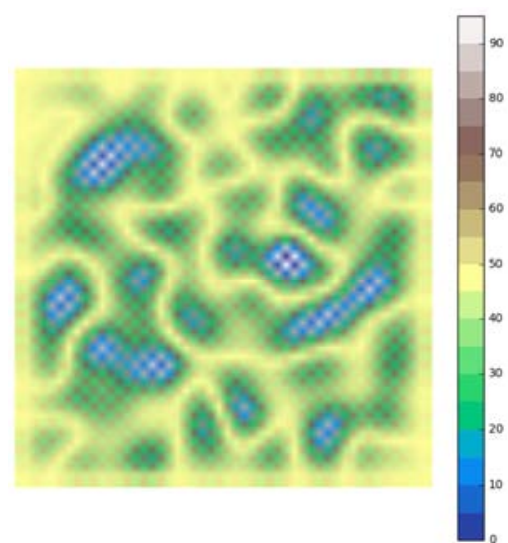

Figure 12. Final Vegetation Pattern of Lower Fertility under Arid Water with a $\beta$-Value of 0.0619864031 .

\subsubsection{Vegetation Pattern of Middle Fertility Under Arid Condition}

The final simulated patterns of the vegetation with a $\beta$-value of 0.0812833722 for middle fertility under arid condition is indicated in Figure 13.

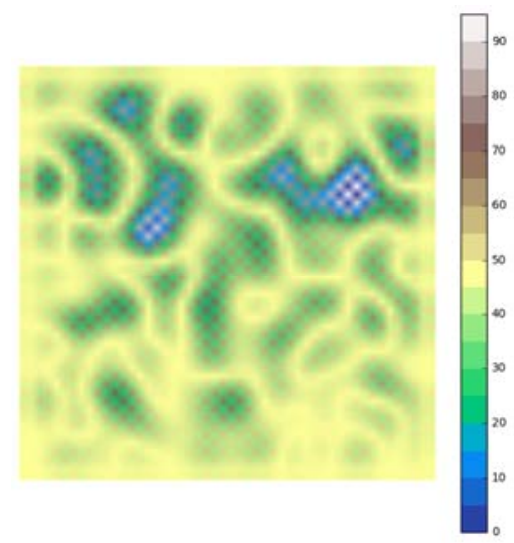

Figure 13. Final Vegetation Pattern of Middle Fertility under Arid Water with a $\beta$-Value of 0.0812833722 .

\subsubsection{Vegetation Pattern of Higher Fertility Under Aridity}

The final simulated patterns of the vegetation with a $\beta$-value of 0.711112388 for higher fertility under arid condition is also shown in Figure 14 below.

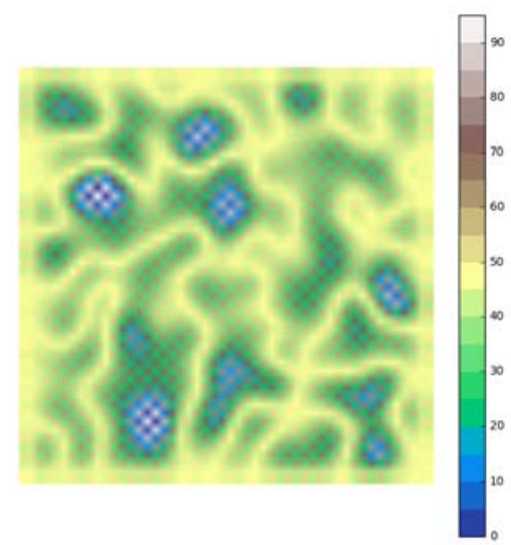

Figure 14. Final Vegetation Pattern of Higher Fertility under Arid Water with a $\beta$-Value of $\beta=0.711112388$.
The level of degradation for various $\beta$-values for control fertility, lower fertility, middle fertility and higher fertility under Arid condition were compared. This is shown in Figure 15.

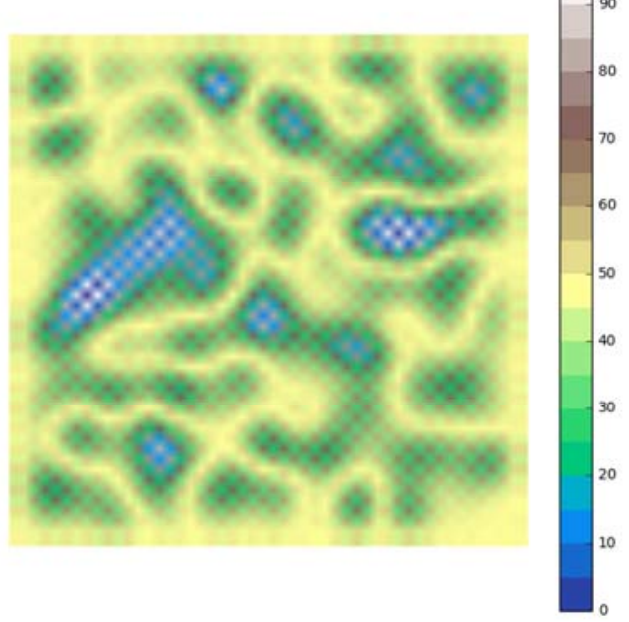

(a) Control Fertility

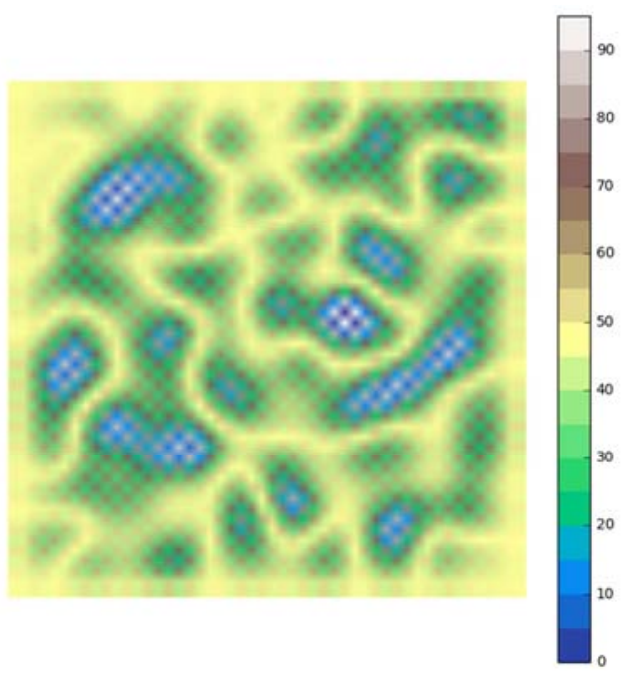

(b) Lower Fertility

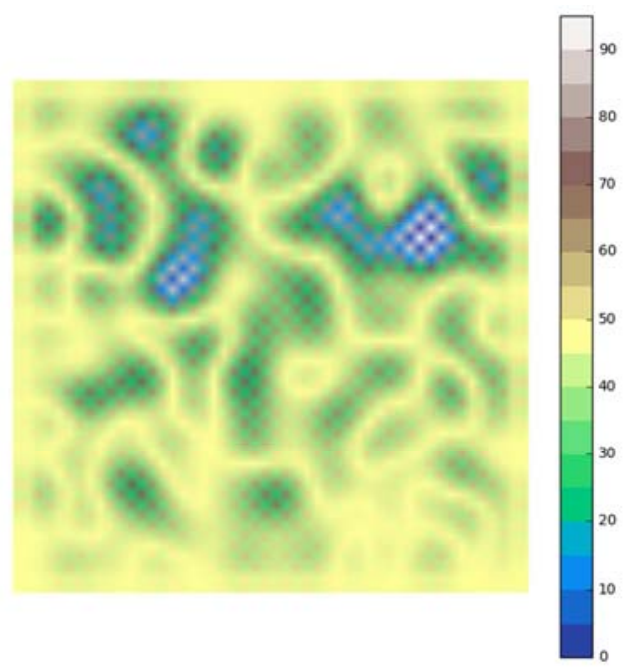

(c) Middle Fertility 


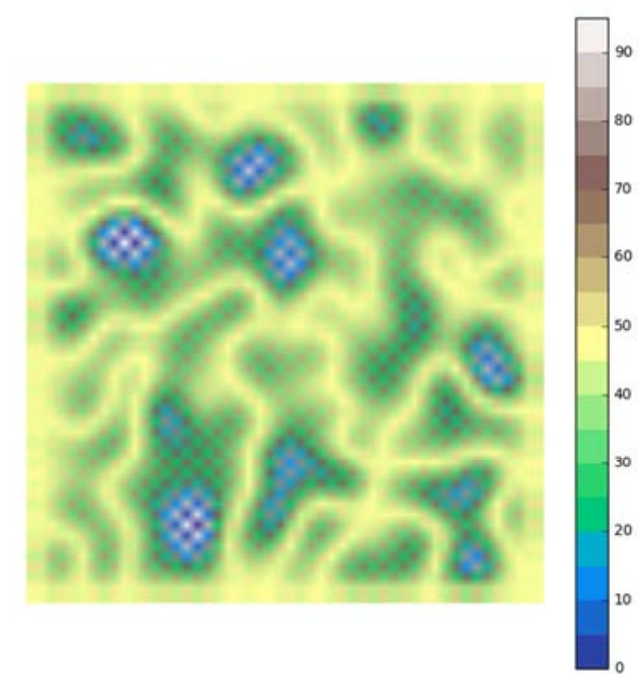

(d) Higher Fertility

Figure 15. Spatial Patterns for Control Fertility, Lower Fertility, Middle Fertility and Higher Fertility of the Soil under Arid Condition.

The spatial patterns generated by the proposed model under different levels of soil fertility namely control fertility, lower fertility, middle fertility and higher fertility based on the state transition parameters, utilisation coefficients and measure indices determined for Arid condition were then compared.

For a $\beta$-value of 0.0560530255 representing the Control fertility under Arid condition, the vegetation shows a pattern with numerous and wider patches of bare or almost bare land compared to patterns exhibited by the other fertility levels as shown by Figure 15a. For a $\beta$-value of 0.0619864031 representing lower fertility, the number of patches of bare or almost bare land formed by the ecosystem reduces. Some of the areas covered by these patches are equally wide and labyrinth in nature, however only a few show some spottily nature. This is shown in Figure 15b. The simulations show a drastic decrease in the number of patches of bare or almost bare land in the case of $\beta=0.0812833722$ for middle fertility. Nonetheless, these few patches are wider and labyrinth in nature. This is equally represented by Figure $15 \mathrm{c}$. When the $\beta$-value is at 0.0711112388 representing higher fertility, more patches of bare or almost bare land were generated than in the case of middle fertility though fewer patches of bare land was expected in the higher fertility than the middle fertility. However, the sizes of the patches of bare land or almost bare land were considerably dwindled compared with situations in the control, lower and middle fertilities. This is shown in Figure 15d.

\section{Discussion of Results}

A mathematical model involving surface water, soil water and biomass dynamics to investigate the dynamics of forest growth and vegetation pattern formation was investigated using a system of nonlinear partial differential equations. The model developed considered the influence of the interactions among multiple resources such as light, water, temperature and nutrients on the growth, and vegetation pattern formation. Michaelis-Menten Kinetics and a ContinuousTime Markov (CTM) method were employed to provide a standardized methodology that describes plant metabolism responses to multiple resource inputs. The CTM technique was then used to obtain a simple plant growth component by synthesizing the four resources (light, water and nutrients together with temperature). The linear stability analysis of homogeneous steady-state solutions provided a reliable predictor of the onset and nature of pattern formation in the reaction-diffusion systems. The results revealed that, stability conditions needed for pattern formation to be satisfied were that, $a N_{0} /\left[a N_{0}+m\left(r N_{0}+l\right)\right] \rightarrow 0$, as $a \rightarrow 0$. Thus, the homogeneous plant equilibrium decreases with decreasing rainfall until plant become extinct. Again, as $N_{0}$ increases or decreases, $a N_{0} /\left[a N_{0}+m\left(r N_{0}+l\right)\right]$ also increases or decreases respectively. This suggest that high $N_{0}$ which is a surrogate for a dimensionless infiltration capacity prohibits pattern formation. Hence, one may not expect vegetation patterns to exist on high fertility level and rich water condition. However, this is not the case. In the non-trivial case, the linear stability analysis of the study shows that the conditions needed for pattern formation to be satisfied is that $r m u<a-l w_{s}$ and $w_{s}>g u$. Thus, ecologically feasible region of the parameter space that gives rise to Turing regimes in which vegetation patterns continuously evolve in space is such that $g u<w_{S}<$ $\frac{(a-r m u)}{l}$. Moreover, numerical simulations of system of partial differential equation model was carried out based on different soil fertility levels under different water conditions. The simulation results show that, regardless of the parameter space, as precipitation rate increases the vegetation cover shifts from uniform to gaps, labyrinths, spots, bare soil or almost bare soil and water condition are also responsible for pattern formation which are consistent with the findings of Rietkerk et al. [34] and D'Odorico et al. [36]. Results of the $\beta$ values for the spatial patterns obtained indicate association or interaction among the various soil fertility levels under different water conditions. Thus, given a $\beta$ value of 0.05605 represents control fertility under arid condition, indicating a vegetation pattern with numerous wider patches of bare or almost bare land.

\section{Conclusion}

The study observes that vegetation patterns on higher fertility level in a given area of rich water condition suggests mechanisms with increasing vegetation biomass, high fertility and a given water condition are responsible for pattern formation. Thus, formation of patterns does not only depend on the low level of fertility but could be as a result of other factors that can equally compensate for the fertility levels and water conditions. The study revealed that because $N_{0}$ which is a surrogate for a dimensionless infiltration capacity prohibits pattern formation, one may not expect vegetation patterns to exist in situations of high fertility level and rich water condition. However, the study has established that vegetation patterns on higher fertility level in a given rich water condition is possible. This suggests that, there 
exists mechanisms other than fertility, water condition and increased infiltration resulting into increased vegetation biomass that are responsible for pattern formation and which to the best of my knowledge, no vegetation pattern model has captured. The study suggest that the model formulated could be used to further analyse the conditions for the development of forest dynamic and their occurrence in different biological systems in Africa. In addition, Agricultural officials should also educate the masses periodically on climate change, vegetation pattern and forest growth to enable farmers cultivate the right vegetation in the right soil to increase production.

\section{References}

[1] Deblauwe, V., Couteron, P., Bogaert, J., Barbier, N., (2012), "Determinants and dynamics of banded vegetation pattern migration in arid climates", Journal of Ecological Monograph, Vol. 82, No. 1, pp 3-21.

[2] Müller, J., (2013), "Floristic and structural pattern and current distribution of tiger bush vegetation in Burkina Faso (West Africa), assessed by means of belt transects and spatial analysis", Application Ecological Environment Res, Vol. 11, pp 53-171.

[3] Berg, S. S., Dunkerley, D. L., (2004), "Patterned mulga near Alice Springs, central Australia, and the potential threat of firewood collection on this vegetation community", Journal of Arid Environment, Vol. 59, pp 313-350.

[4] Moreno-de las Heras, M., Saco, P. M., Willgoose, G. R., Tongway, D. J., (2012), "Variations in hydrological connectivity of Australian semiarid landscapes indicate abrupt changes in rainfall-use efficiency of vegetation", Journal of Geophys Res Vol. 117, pp G03009.

[5] Pelletier, J. D., DeLong, S. B., Orem, C. A., Becerra, P., Compton, K., Gressett, K., Lyons-Baral, J., McGuire, L. A., Molaro, J. L., Spinler, J. C., (2012), "How do vegetation bands form in dry lands? Insights from numerical modeling and field studies in southern Nevada. USA", Journal of Geophys Res, Vol. 117, pp F04026.

[6] Penny, G. G., Daniels, K. E., Thompson, S. E., (2013), “Local properties of patterned vegetation: quantifying endogenous and exogenous effects", Philos Trans R Soc A, Vol. 371, pp 20120359 .

[7] Buis, E., Veldkamp A., Boeken, B., Van Breemen, N., (2009), "Controls on plant functional surface cover types along a precipitation gradient in the Negev Desert of Israel", Journal of Arid Environment, Vol. 73, pp 82-90.

[8] Sheffer, E., von Hardenberg, J., Yizhaq, H., Shachak, M. and Meron, E., (2013), "Emerged or imposed: a theory on the role of physical templates and self-organisation for vegetation patchiness", Ecology letters, Vol. 16, No. 2, pp. 127-139.

[9] Yizhaq, H., Sela, S., Svoray, T., Assouline, S., Bel, G., (2014), "Effects of heterogeneous soil-water diffusivity on vegetation pattern formation", Water Resour Res, Vol. 50, pp 5743-5758.

[10] Deblauwe, V., Barbier, N., Couteron, P., Lejeune, O., Bogaert, J., (2008), "The global biogeography of semi-arid periodic vegetation patterns", Glob Ecol Biogoegr Vol. 17, pp 715723.
[11] Deblauwe, V., Couteron, P., Lejeune, O., Bogaert, J., Barbier, N., (2011), "Environmental modulation of selforganized periodic vegetation patterns in Sudan", Journal of Ecography, Vol. 34, pp 990-1001.

[12] Meron, E., (2012), "Pattern-formation approach to modelling spatially extended ecosystems", Ecological Model, Vol. 234, pp 70-82.

[13] Bel, G., Hagberg, A., Meron, E., (2012), "Gradual regime shifts in spatially extended ecosystems", Journal of Theoretical Ecology, Vol. 5, pp 591-604.

[14] Dralle, D., Boisrame, G., Thompson, S. E., (2014), "Spatially variable water table recharge and the hillslope hydrologic response: Analytical solutions to the linearized hillslope Boussinesq equation", Journal of Water Resources Research, Vol. 50, pp 8515-8530.

[15] Bouldin, D. R., (1961), "Mathematical description of diffusion processes in the soil-plant system", Soil Science Society of America Proceedings No 25: pp 476-480.

[16] Olsen, S. R., Kemper, W. D., and Jackson, R. D., (1962), "Phosphate diffusion to plant roots". Soil Science Society of America Proceedings Vol. 26, pp 222-227.

[17] Nye, P. H. and Spiers,. J. A., (1964), "Simultaneous diffusion and mass flow to plant roots. p. 535-541 In (editors missing.) Transactions: 8th International Congress of Soil Science, Bucharest, Romania, 31 Aug. -9 Sep. 1964. Publishing House of the Academy of the Socialist Republic of Romania, Rompresfilatelia, Bucharest.

[18] Nye, P. H., and Marriott, F. H. C., (1969), "A theoretical study of the distribution of substances around roots resulting from simultaneous diffusion and mass flow", Journal of Plant and Soil, Vol. 30, pp 459-472.

[19] Baldwin, J. P., Nye, P. H., Tinker, P. B., (1973), "Uptake of solutes by multiple root systems from soil III - a model for calculating the solute uptake by a randomly dispersed root system developing in a finite volume of soil", Journal of Plant and Soil, Vol 38, pp 621 - 635.

[20] Barber, S. A and Cushman, J. H., (1981), "Nitrogen uptake model for agronomic crops", pp. 382-409 In I. K. Iskandar (ed.). Modeling waste water renovation-land treatment: WileyInterscience, New York.

[21] Smethurst, P. J., Mendham, D. S., Battaglia, M. and Misra, R., (2004), "Simultaneous prediction of nitrogen and phosphorus dynamics in a Eucalyptus nitens plantation using linked CABALA and PCATS models", pp. 565-569 In N. M. G. Borralho (ed.) Eucalyptus in a changing world. Proceedings of an International conference of the WP2.08.03 on silviculture and improvement of eucalypts, Aveiro, Portugal, 11-15 October 2004. IUFRO, Aveiro, Portugal.

[22] Comerford, N. B., Cropper, W. P. Jr., Hua, L., Smethurst, P. J. K., Van Rees, C. J., Jokela, E. J., Adams, F., (2006), "Soil Supply and Nutrient Demand (SSAND): a general nutrient uptake model and an example of its application to forest management", Canadian Journal of Soil Science, Vol. 86, pp 655-673.

[23] Wu, R., Yankaskas, J., Cheng, E., Knowles, M. and Boucher, R., (1985), "Growth and differentiation of human nasal epithelial cells in culture: serum-free, hormone-supplemented medium and proteoglycan synthesis", American Review of Respiratory Disease, Vol. 132, No. 2, pp. 311-320. 
[24] Wu, J. C., Merlino, G. and Fausto, N., (1994), "Establishment and characterization differentiated, nontransformed hepatocyte cell lines derived from mice transgenic for transforming growth factor alpha", Proceedings of the National Academy of Sciences, Vol 91, No 2, pp. 674-678.

[25] Sharpe, P. J. H., Walker, J., Wu, I. (1985), "Physiologically based continuous-time Markov approach of plant growth modelling in semi-arid woodlands", Journal of Ecological Modelling, Vol. 29, No 15, pp 189 - 213.

[26] Temesgen, H. and Gadow, K. V., (2004), "Generalized heightdiameter models-an application for major tree species in complex stands of interior British Columbia", European Journal of Forest Research, Vol. 123, No. 1, pp. 45-51.

[27] Gowda, K., Riecke, H., Silber, M., (2014), "Transitions between patterned states in vegetation models for semiarid ecosystems", Phys Rev E, Vol. 89, 022701.

[28] Rietkerk, M., Dekker, S. C., de Ruiter, P. C., van de Koppel, J., (2004), "Self-organized patchiness and catastrophic shifts in ecosystems", Science, Vol. 305, pp 1926-1929.

[29] Kéfi, S., Rietkerk, M., van Baalen, M., Loreau, M., (2007), "Local facilitation, bistability and transitions in arid ecosystems", Theoretical Population Biology Vol. 71, pp 367379 .
[30] Corrado, R., Cherubini, A. M., Pennetta, C., (2014), "Early warning signals of desertification transitions in semiarid ecosystems", Journal of Physical Review Education, Vol. 90, pp. 062705-1 to 062705-11.

[31] Klausmeier, C. A., (1999), "Regular and irregular patterns in semiarid vegetation", Science, Vol. 284, pp 1826-1828.

[32] Li, Y. R., (2003), "Contraction integrated semigroups and their application to continuous- time Markov chains", Acta Mathematica Sinica, Vol. 19, No 3, pp. 605-618.

[33] Walker, B. H., Ludwig, D., Holling, C. S., Peterman, R. M., (1981), "Stability of semi-arid savanna grazing systems", Journal of Ecology, Vol. 69, pp 473-498.

[34] Rietkerk, M., van den Bosch, F., van de Koppel, J. V., (1997), "Site-specific properties and irreversible vegetation changes in semi-arid grazing systems", Oikos, Vol. 80, No. 1, pp. 241252.

[35] de Wit, C. T., (1958), "Transpiration and crop yields", Unknown Publisher, No. 64. 6.

[36] D'Odorico, P., Caylor, K., Okin, G. S. and Scanlon, T. M., (2007), "On soil moisture- vegetation feedbacks and their possible effects on the dynamics of dryland ecosystems", Journal of Geophysical Research: Bio geosciences, Vol. 112, No. G4. 